\title{
Biological Activities of Nerve Growth Factor Bound to Nitrocellulose Paper by Western Blotting
}

\author{
Brigitte Pettmann, Marston Manthorpe, Jo Anne Powell, and Silvio Varon \\ Department of Biology, University of California San Diego, La Jolla, California 92093
}

\begin{abstract}
We have previously developed a cell-blot technique to visualize directly in tissue extracts molecules that display the biological activity of ciliary neuronotrophic factors (CNTFs). This technique involves SDS-PAGE of the tissue extract, Western blotting on nitrocellulose paper, neuronal cell culture on the paper, and, using a vital dye, visualization of the neurons that selectively survive on the trophic factor band. In this report, we show that (1) NGF, either purified or in a crude extract from submaxillary glands, can also be successfully recognized using a slightly modified cell-blot technique; (2) a variety of ganglionic neurons can respond to distinct nitrocellulose-anchored trophic factors; (3) while CNTF and NGF can both support the survival of their common target cells, only NGF also promotes neuritic extension; and $(4)$ both the dimeric and the monomeric forms of immobilized $\beta$-NGF are active.
\end{abstract}

Different types of neurons from the CNS and PNS require different types of trophic factors for their survival and functional maintenance in vivo and in vitro (Varon and Adler, 1981; Varon 1985; Levi-Montalcini, 1987). Such neuronotrophic factors were identified and purified using in vitro bioassays, in which monolayer cultures of the target neuronal cells are incubated in medium containing the factor. For one of them, the ciliary neuronotrophic factor (CNTF), a method was developed to determine the molecular mass of the active molecule from a crude preparation. This method, termed the "cell-blot" technique (Carnow et al. 1985; Rudge et al., 1987), involves SDSPAGE of the extract containing the active molecule followed by electrophoretic transfer of the resolved proteins to nitrocellulose paper. The target cells [in this case, embryonic day eight (E8) chick ciliary ganglionic motor neurons] were then cultured on the paper and neuronal cell survival after $24 \mathrm{hr}$ was visualized by the cell's ability to internalize the vital dye MTT and transform it into a blue water-insoluble product. The cell-blot technique showed that the ciliary ganglionic neurons survive only on 2 protein bands with apparent molecular masses of 24 and $28 \mathrm{kDa}$, in agreement with the molecular properties of the purified CNTFs (Barbin et al., 1984; Manthorpe et al., 1986; Rudge et al., 1987). Besides permitting the determination of the mo-

\footnotetext{
Received Dec. 15, 1987; revised Feb. 15, 1988; accepted Mar. 3, 1988.

This work was supported by the Grant NS-16349 and NS-25011 from NIH and BNS 86-17034 from NSF. Dr. Pettmann is on leave from INSERM (France). We gratefully acknowledge the expert technical assistance of Ms. Eleanore Hewitt, Ms. Teresa Haddow, and Mr. David Kon.

Correspondence should be addressed to Dr. Marston Manthorpe, Department of Biology M-001, University of California San Diego, La Jolla, CA 92093.

Copyright (C) 1988 Society for Neuroscience $0270-6474 / 88 / 103624-09 \$ 02.00 / 0$
}

lecular mass of the active molecule without prior purification, these results indicate that CNTF can exert its effect on cell survival from a surface-anchored position, as well as from the humoral environment.

The present study was undertaken to extend this technique to another neuronotrophic factor, NGF, and to other probe cells such as sensory and sympathetic neurons. The $26 \mathrm{kDa}$ active dimer of NGF was successfully visualized using a slightly modified cell-blot technique. Nitrocellulose-bound NGF and CNTF are recognized by their respective target neurons in the same way as when the factors are in solution in a culture medium. As with CNTF, the NGF activity can be seen in crude extracts of source tissue. Furthermore, an aldehyde-fixation and staining of the cell-blot culture for neurofilament proteins permits the visualization of neuritic outgrowth, as well as the neuronal survival. In this way, it was possible to demonstrate a differential effect of NGF and CNTF on the same probe neurons. NGF supports survival and stimulates neuritic outgrowth of neurons derived from E10 chick dorsal root ganglia, while CNTF is only able to support their survival. Depending on specific sample treatments preceding the electrophoresis, one can resolve the loaded NGF into either the dimeric form of $\beta$-NGF ( $26 \mathrm{kDa})$ or its monomeric form $(13 \mathrm{kDa})$, and both species express biological activity after being blotted onto nitrocellulose paper.

\section{Materials and Methods}

Preparation of tissue extracts and purified neuronotrophic factors. The CNTF-containing extract of E15 chick intraocular tissues-including the choroid, iris-ciliary body, and pigment epithelium (CIPE) - was prepared as reported (Manthorpe et al., 1980) and purified rat nerve CNTF was prepared as described (Manthorpe et al., 1986). Mouse submaxillary gland extract and purified NGF (7S form or $\beta$ form) were prepared as described (Varon et al., 1972).

Electrophoresis. Samples containing the trophic factors were mixed with electrophoresis sample buffer $(0.0625$ м Tris-HCl, $2.3 \%$ SDS, $10 \%$ glycerol, and $0.05 \%$ bromophenol blue, $\mathrm{pH} 6.8$ ). In some cases only, the samples were further boiled for $5 \mathrm{~min}$ in the presence or absence of $5 \% \beta$-mercaptoethanol. Samples were applied on a $15-25 \%$ linear gradient SDS-polyacrylamide slab gel (gel buffer $=0.75 \mathrm{M}$ Tris- $\mathrm{HCl}, 0.1 \%$ SDS, $\mathrm{pH} 8.3$ ) with a $4.5 \%$ stacking gel (gcl buffer $=0.125 \mathrm{~m}$ Tris- $\mathrm{HCl}$, $0.1 \% \mathrm{SDS}, \mathrm{pH} 6.8$ ). Electrophoresis was carried out for $16-18 \mathrm{hr}$ at 250 $\mathrm{V}$ in a Bio-Rad dual vertical slab gel apparatus with cooling, in an electrophoresis buffer consisting of $50 \mathrm{~mm}$ Tris and $192 \mathrm{~mm}$ glycine, $0.1 \%$ SDS, $\mathrm{pH}$ 8.3. The apparent molecular masses of the separated proteins were determined using prestained molecular weight markers (Rainbow, Amersham Corporation, UK) containing myosin $200 \mathrm{kDa}$, phosphorylase b $92.5 \mathrm{kDa}$, BSA $69 \mathrm{kDa}$, ovalbumin $46 \mathrm{kDa}$, carbonic anhydrase $30 \mathrm{kDa}$, trypsin inhibitor $21.5 \mathrm{kDa}$, and lysozyme $14.3 \mathrm{kDa}$, as well as unstained molecular-weight marker proteins (Bio-Rad Laboratories: same proteins as above except without myosin).

Electroblotting and staining. After electrophoresis, proteins were electrophoretically blotted onto nitrocellulose paper essentially according to the method of Towbin et al. (1979). The blotting buffer consisted of 
$25 \mathrm{~mm}$ Tris, $192 \mathrm{~mm}$ glycine, and $20 \%$ methanol, $\mathrm{pH}$ 8.3. In some cases, $0.1 \%$ SDS was added to this buffer. The transfer was performed in a Hoeffer blotting apparatus at $100 \mathrm{~mA}$ for $16 \mathrm{hr}$ at $4^{\circ} \mathrm{C}$. Some of the resulting Western blots were used for (1) staining of the blotted proteins with Aurodye (Janssen) or (2) immunostaining for NGF antigen. For the immunostaining procedure, the blots were washed with PBS containing $0.1 \%$ Tween 20 (PBS-Tween); unoccupied protein-binding sites on the paper were blocked by incubating the blots with 1\% BSA in PBSTween for $1 \mathrm{hr}$ at room temperature; the blots were then incubated overnight at $4^{\circ} \mathrm{C}$ with primary antibodies directed against $2.5 \mathrm{~S}$ NGF (rabbit anti-NGF, Collaborative Research, Inc.) diluted 1:200 in PBSTween $+1 \%$ BSA; after $3 \times 10$ min washes with PBS-Tween, the NC papers were incubated for $2 \mathrm{hr}$ at room temperature with peroxidaseconjugated goat anti-rabbit immunoglobulins (Cappel, Cooper Biomedical) diluted 1:200 in PBS-Tween $+1 \%$ BSA; after $3 \times 10$ min washes with PBS-Tween, the bound peroxidase was revealed using 4-chloro-1naphthol $(50 \mathrm{mg}$ in $100 \mathrm{ml}$ of $0.9 \% \mathrm{NaCl})$ as the substrate in the presence of $\mathrm{H}_{2} \mathrm{O}_{2}(20 \mu \mathrm{l})$.

Cell blots. The blots were rinsed with PBS. The position of the molecular-weight markers was marked on the sample lanes with a pin, using as guides the lanes of prestained marker proteins run on both ends of the gels. The free protein-binding sites were blocked by incubating the nitrocellulose papers for $1 \mathrm{hr}$ at room temperature with $1 \%$ ovalbumin in PBS containing antibiotics $(100 \mu \mathrm{g} / \mathrm{ml}$ penicillin, $100 \mu \mathrm{g} / \mathrm{ml}$ streptomycin, and $0.25 \mu \mathrm{g} / \mathrm{ml}$ fungizone) to prevent subsequent contamination when the paper is placed in culture. The blots were then cut into strips corresponding to individual lanes or groups of lanes and transferred to rectangular culture chambers. Last, the blots were washed with culture medium (DMEM $+10 \%$ fetal calf serum + antibiotics) and incubated with $5 \mathrm{ml}$ of the same medium for $20 \mathrm{~min}$ before cell seeding. Neurons from 4 types of embryonic chick ganglia were used in these studies: E8 ciliary (CG8), E8 and E10 dorsal root (DRG8, DRG10), and E12 sympathetic (SG12) ganglia. In all cases, ganglia were dissociated into single-cell suspensions, and neurons were enriched to more than $90 \%$ purity by differential attachment to tissue culture plastic dishes (Varon et al., 1979; Varon and Adler, 1981; Selak et al. 1983; Davis et al., 1985). Neurons were diluted in culture medium to $6 \times 10^{4} / \mathrm{ml}$ and $5 \mathrm{ml}$ added to each blot strip for a seeding density of $10^{4}$ neurons $/ \mathrm{cm}^{2}$ of paper. Cell blots were cultured for $48 \mathrm{hr}$ instead of the $24 \mathrm{hr}$ previously reported (Carnow et al., 1985; Rudge et al., 1987) to decrease the number of "background" surviving neurons. For the last $2 \mathrm{hr}$, the cell blot cultures were incubated with a solution of MTT [3-(4,5-dimethylthiazol2 -yl)-2,5-diphenyl tetrazolium bromide], at a final concentration of 0.5 $\mathrm{mg} \mathrm{MTT} / \mathrm{ml}$ of medium. Alternatively, the $48 \mathrm{hr}$ cultures were fixed for $30 \mathrm{~min}$ in a solution of $4 \%$ paraformaldehyde in PBS and immunostained for neurofilament proteins, using a mouse monoclonal antibody (RT 97 , kindly provided by Dr. Frank Walsh) and a HRP conjugated secondary antibody as described by Davis et al. (1987).

\section{Results}

\section{Adaptation of the cell-blot method to the study of NGF}

When applied to 7S NGF, the cell-blot method developed for CNTF did not work. We studied in detail each step of the procedure and found that 2 of them had to be modified.

1. In the original method, the CNTF was loaded on the polyacrylamide gel in a "sample buffer" containing a reducing agent, $\beta$-mercaptoethanol, which inactivates NGF (data not shown, but see below). Therefore, 7S NGF was loaded on the gel in a sample buffer containing no reducing agent.

2. In the original method, the CNTF was electrophoretically transferred from the gel to the nitrocellulose paper in a "blotting buffer" containing $0.192 \mathrm{M}$ glycine, $0.025 \mathrm{M}$ Tris, and $20 \%$ methanol, $\mathrm{pH}$ 8.6. We found that, to get an efficient transfer of the basic NGF to the nitrocellulose paper, we had to introduce $0.1 \%$ SDS into the blotting buffer [data not shown; see also Aebersold et al. (1987)]. Table 1 summarizes the conditions used in the present cell-blot procedures for NGF and CNTF.

Applying the appropriate blotting conditions for each factor, blots were used as substrata for cultured neurons as described in Materials and Methods. The 7S NGF blot was probed with
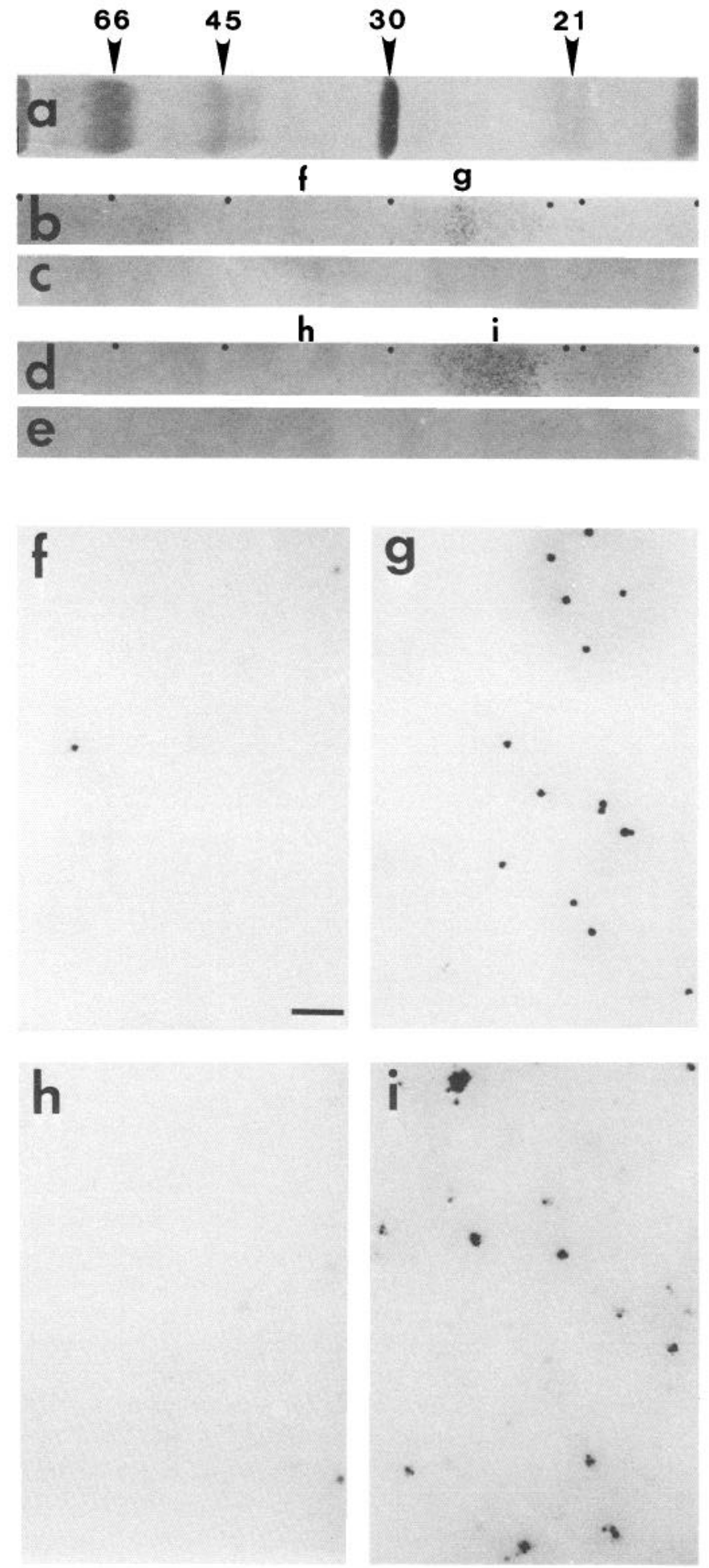

Figure 1. Western blots of NGF and ciliary neuronotrophic factor (CNTF), cultured for $48 \mathrm{hr}$ with E8 chick ciliary ganglionic (CG8) and E8 chick dorsal root ganglionic (DRG8) neurons, and stained with a vital dye. $a$, Blot of standard proteins stained with Amido black. Blots of $10 \mathrm{ng}$ of rat nerve CNTF, seeded with $(b)$ CG8 or $(c)$ DRG8 neurons. Blots of $10 \mathrm{ng}$ of mouse submaxillary gland NGF, seeded with $(d)$ DRG8 or $(e)$ CG8 neurons. Higher magnification of areas outside $(f, h)$ or on $(g, i)$ the indicated region of the protein bands shown in $b$ and $d$. Scale bar, $100 \mu \mathrm{m}$. 
Figure 2. Numerical distribution of probe neurons along the cell blots of Figure 1. Peaks of surviving neuronal numbers identify the apparent molecular mass of the corresponding trophic factor protein.

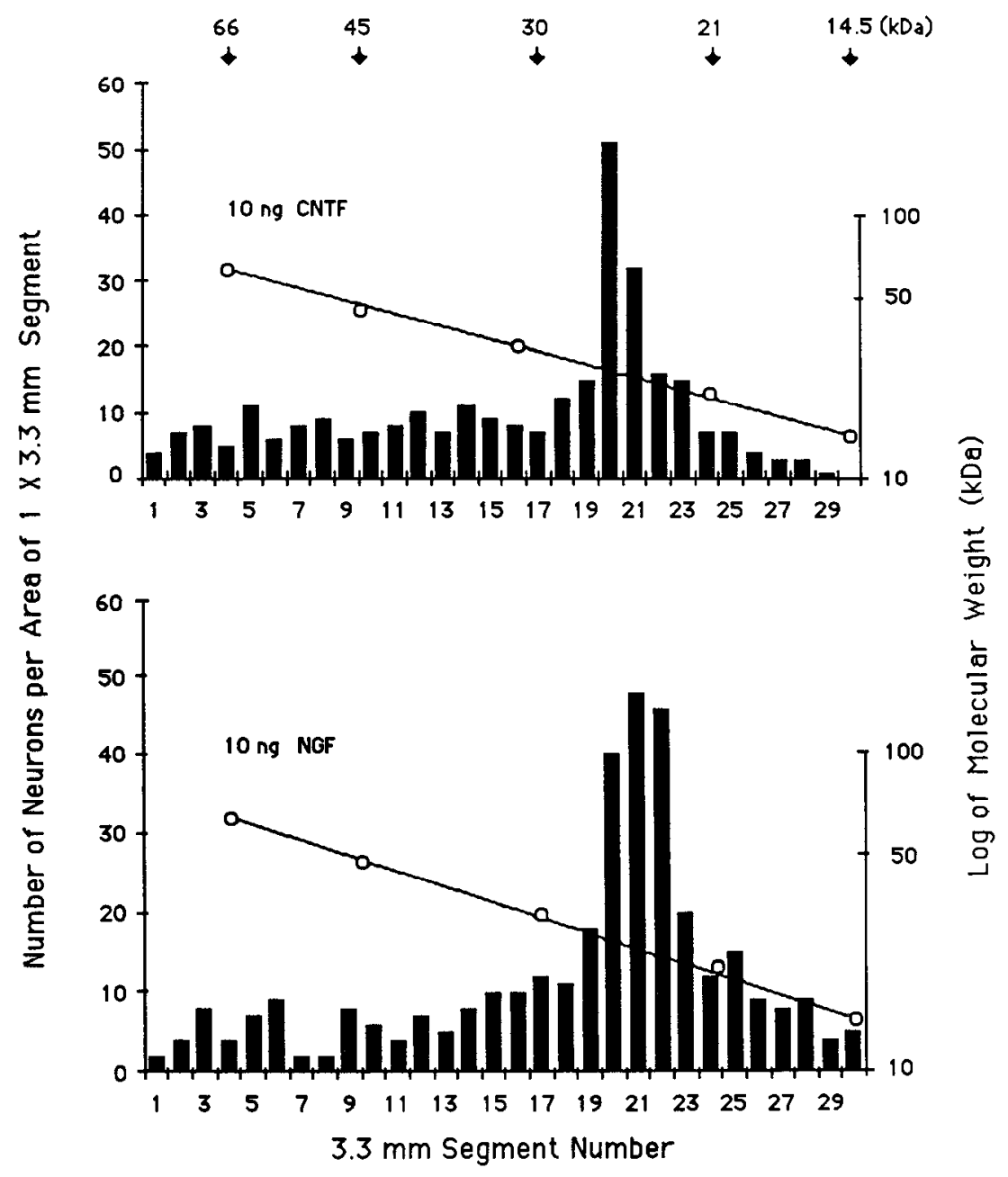

DRG8 neurons, while the CNTF blot was probed with CG8 neurons. The results are shown in Figure 1. At low magnification (Fig. 1, $b$ and $d$ ), the trophic band can be recognized in both cases by naked eye inspection. The NGF band is generally wider than the CNTF band. When the cell blots are examined at a higher magnification (Fig. $1, f-i$ ), there is an unequivocal contrast between the low cell density of MTT-stained neurons in the off-band regions (Fig. 1, $f$ and $h$ ) and their high density in the on-band areas (Fig. 1, $g$ and $i$ ). At this higher magnification, the number of cells can be counted throughout the total length of the blot paper. Such quantitative scans, illustrated in Figure 2, can be used to determine apparent molecular masses of CNTF and NGF, which were found to be $28 \mathrm{kDa}$ and $24-27 \mathrm{kDa}$,

$\begin{aligned} & \text { Table 1. Different conditions required for the cell-blot detection of } \\ & \text { rat CNTF and mouse NGF }\end{aligned}$
Additives

${ }^{a}$ Electrophoretic gel loads $=10 \mathrm{ng} /$ lane. respectively. The CNTF molecular mass of $28 \mathrm{kDa}$ agrees well with that already assigned to rat CNTF by the blot technique (Rudge et al., 1987). The NGF values agree with the 26,500 $\mathrm{kDa}$ molecular mass determined by other means for the $\beta$-NGF dimer (Angeletti and Bradshaw, 1971), demonstrating that (1) the active dimer form is retained through SDS exposures (at room temperature) during both electrophoretic and blotting steps, and (2) the NGF dimer can express its trophic action in a surfaceanchored position as well as in solution. Cell counts were also used to determine the sensitivity of the method, which for both factors allows the detection of as little as $10 \mathrm{ng}$ loads per lane (data not shown).

\section{Identification of the NGF band}

Confirmation of the NGF nature of the $26 \mathrm{kDa}$ band on which DRG8 neurons were surviving was sought by several approaches. A load of $1 \mu \mathrm{g}$ of $\beta-\mathrm{NGF}$, instead of the 7S NGF, was processed through the SDS gel electrophoresis and Western blot steps, and the blots were stained (1) for protein with Aurodye or (2) for NGF antigen with anti-mouse NGF antiserum. Other blots, obtained from $100 \mathrm{ng} \beta$-NGF loads, were treated overnight at $4^{\circ} \mathrm{C}$ with a dilution of $1: 100$ of rabbit anti-NGF antiserum or with a control antiserum [against rabbit anti-glial fibrillary acidic protein (GFAP)]. The blots were then washed $3 \times$ 10 min with PBS-Tween and $2 \times 30$ min with culture medium and used for cell seeding with DRG8 neurons. Figure 3 illus- 


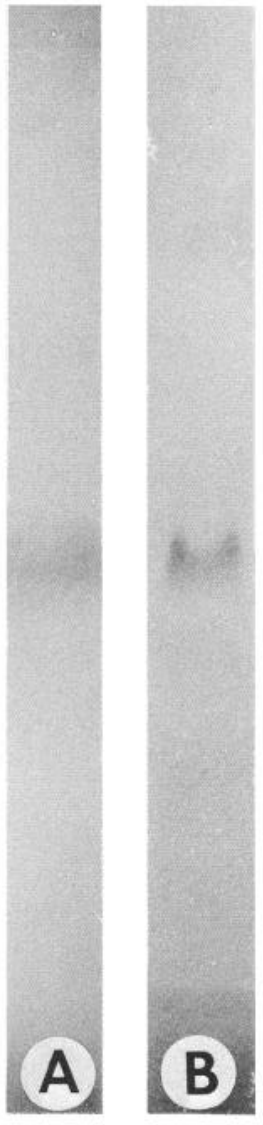

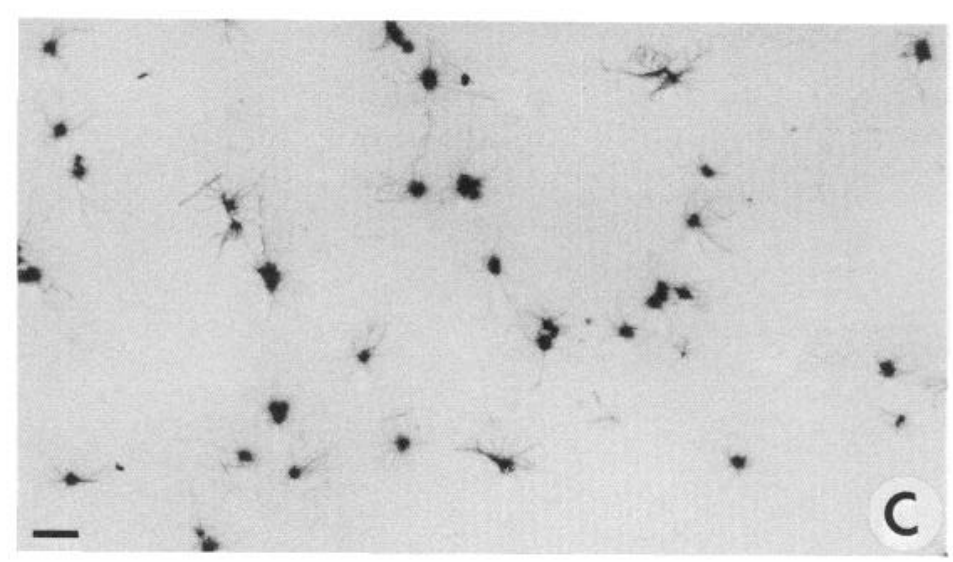

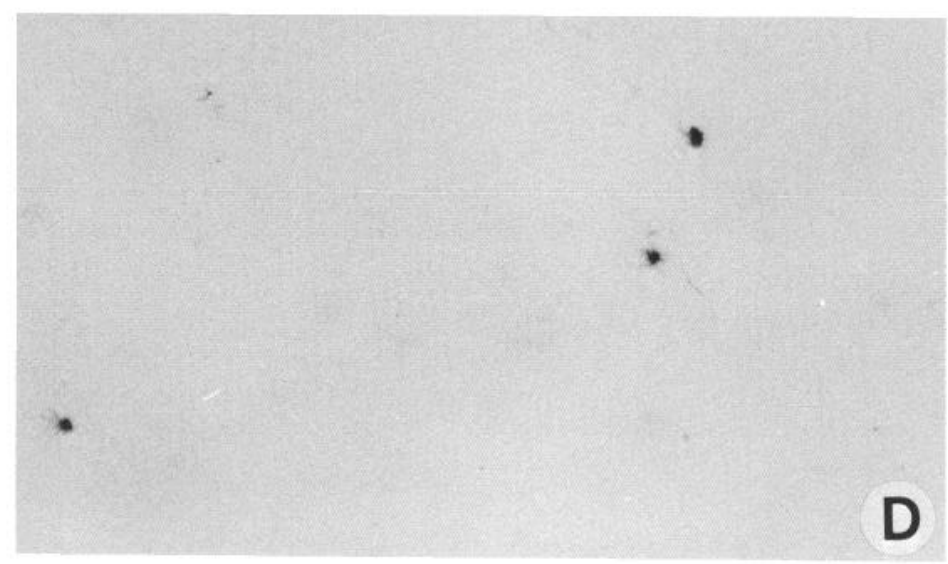

Figure 3. Western blots of $1 \mu \mathrm{g} \beta$-NGF stained with Aurodye $(A)$ or immunostained with anti-mouse NGF antiserum $(B) . C$ and $D$, Magnification of the $26 \mathrm{kDa}$ region of blots of $100 \mathrm{ng} \beta$ NGF, incubated with either anti-glial fibrillary acidic protein antiserum $(C)$ or anti-mouse NGF antiserum $(D)$, then seeded with DRG8 neurons and probed after $48 \mathrm{hr}$ for cell survival with MTT. (Note the presence of numerous formazan crystals resulting from the reduction of the vital dye, MTT, by the viable cells.) Scale bar, $100 \mu \mathrm{m}$. trates the results. Both the protein dye $(A)$ and the immunostaining $(B)$ revealed a wide band at $26 \mathrm{kDa}$. The $26 \mathrm{kDa}$ band from $\beta$-NGF incubated with the control anti-GFAP antiserum supported the survival of DRG8 neurons $(C)$, while no survival could be shown after treatment of the blot with anti-NGF antiserum $(D)$.

\section{Evaluation of CNTF and NGF cell blots by neurofilament protein immunostaining}

In previous work with CNTF cell blots, the MTT-stained CG8 probe neurons have always appeared round, smooth-contoured, and with no obvious staining of individual neurites (see Fig. $1 \mathrm{~g}$ ). However, the lack of demonstrable neurites from MTTstained cells does not preclude the possibility that nitrocellulosebound neurons have grown neurites. Studies with traditional microplate cultures have shown that individual neurites do not stain well with the MTT dye. Therefore, to detect neuritic outgrowth, CNTF and 7S NGF cell blots were fixed without exposing them to MTT and immunostained for neurofilament proteins. The results are shown in Figure 4. Neurofilament protein staining considerably raised the background level of countable cells by adding those cells that exclude MTT (hence, are presumably not viable) but retain the neurofilament protein antigens. The CNTF cell blot, probed with their traditional CG8 neurons, appeared qualitatively similar when stained for neurofilament proteins or with MTT, i.e., no neuritic outgrowth could be seen. In contrast, the NGF cell blot displayed a very robust neurite outgrowth from most of the DRG8 neurons used as probes. Neuritic outgrowth was confined to the "on-band" region. The "off-band" regions showed a higher background number of neurons than with the MTT stain (as with the CNTF cell blot) but practically no evidence of neurites.

These results indicate that (1) neurites can grow on a nitrocellulose blot and may be visualized with an anti-neurofilament antibody, (2) surface-anchored neuronotrophic factors may also act as neurite-promoting substrata, and (3) neurites are elicited either by blotted NGF but not by blotted CNTF or from DRG8 but not CG8 neurons.

\section{Use of different ganglionic neurons to probe CNTF and NGF cell blots}

As the studies described above, CNTF and NGF activities were monitored in vitro by testing their effect on the survival of their respective specific target neurons. However, these growth factors can also act on common target cells, such as DRG10 and SG12 neurons. In view of this partially overlapping spectrum of target cells, we studied the ability of these 2 neuronal types to respond to immobilized CNTF or NGF. Cultures were stained for neurofilament protein, rather than with MTT, to evaluate neurite outgrowth as well as survival.

Figure 5 illustrates the appearance, on CNTF and 7S NGF cell blots, of probe neurons susceptible to trophic support by both factors. Beside the expected higher background, the CNTF cultures revealed that, in all cases, the DRG10 or SG12 neurons surviving on the CNTF band exhibited little if any neuritic outgrowth. Once again, the same neurons displayed considerable neuritic growth over the blotted NGF band, demonstrating that the neuritic behavior was dictated more by the type of trophic factor presented on the nitrocellulose paper than by the type of neurons used as probes. DRG10 neurons responded as 


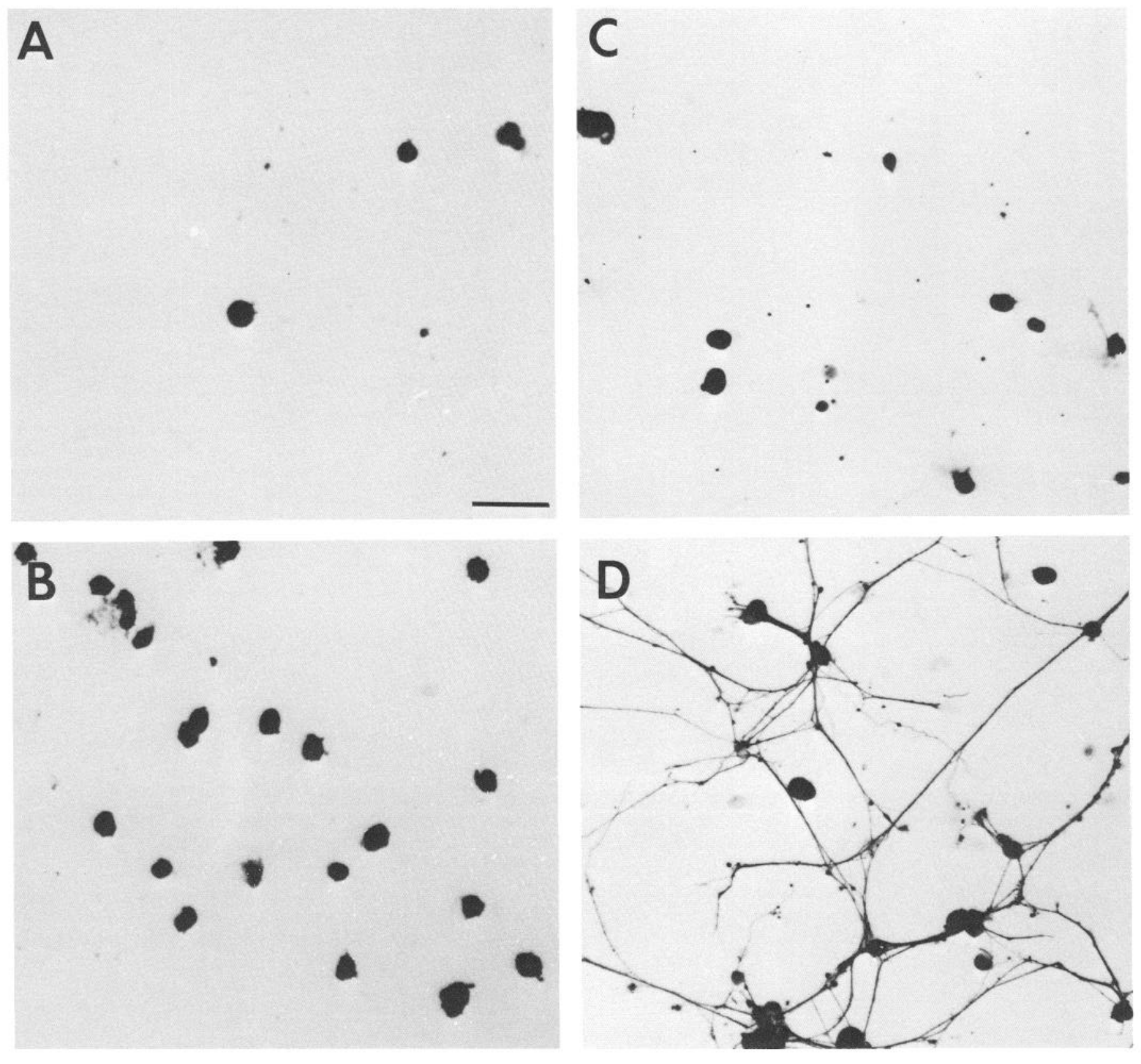

Figure 4. Photographs of $\operatorname{CNTF}(A, B)$ and $\operatorname{NGF}(C, D)$ cell-blot fields, outside $(A, C)$ or on $(B, D)$ the trophic protein band. Cell blots, carried out under the same conditions as in Figure 1, were fixed and stained by immunohistochemistry for neurofilament protein. Scale bar, $50 \mu \mathrm{m}$.

vigorously to NGF as the DRG8 neurons. With SG12 neurons the neuritic outgrowth elicited by NGF was less robust than that observed with DRG10 neurons.

\section{Cell blots of crude extracts}

To test the selective properties of the cell-blot systems, we cultured CG8 and DRG8 neurons on blots of crude extracts known to contain one or the other factor, i.e., for the CNTF, CIPE extract and rat nerve extract and for the NGF, mouse submaxillary gland extract. Each crude extract was submitted to the 2 different gel-blot conditions (i.e., with or without SDS; see Table 1) necessary to recognize NGF and CNTF. The results are shown in Table 2. CG8 neurons survived on CIPE and rat nerve extract protein bands having apparent molecular masses of 24 and 28 $\mathrm{kDa}$, respectively, as shown by Rudge et al. (1987). DRG8 neu- rons survived only in the 24-27 kDa region of the submaxillary gland extract. Thus, the cell-blot method allows (1) the detection of trophic factors in complex mixtures of proteins and (2) the specific identification of the trophic factors contained in an extract. Our observations show also that the differential conditions required for each type of blot apply to the crude as well as to the purified factors.

\section{Dimeric and monomeric forms of $\beta-N G F$}

Beta-NGF normally occurs in its dimeric, $26 \mathrm{kDa}$ form. Disulfide bond reduction in the absence of denaturating agents does not convert the dimer to its monomers (Greene et al., 1971). Conversion is also not noticeable with SDS in the mild conditions used here ( $30 \mathrm{~min}$ at room temperature in the sample buffer, plus $16 \mathrm{hr}$ at $4^{\circ} \mathrm{C}$ during SDS gel electrophoresis). On 


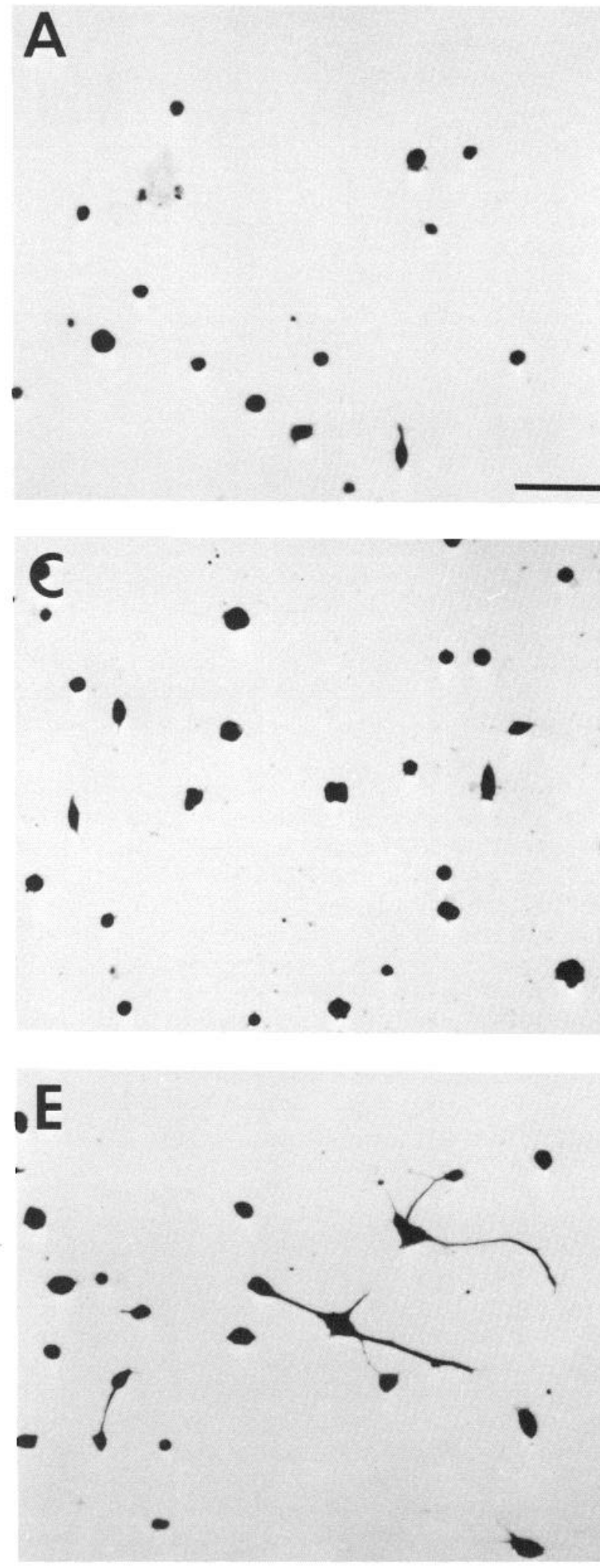

B 

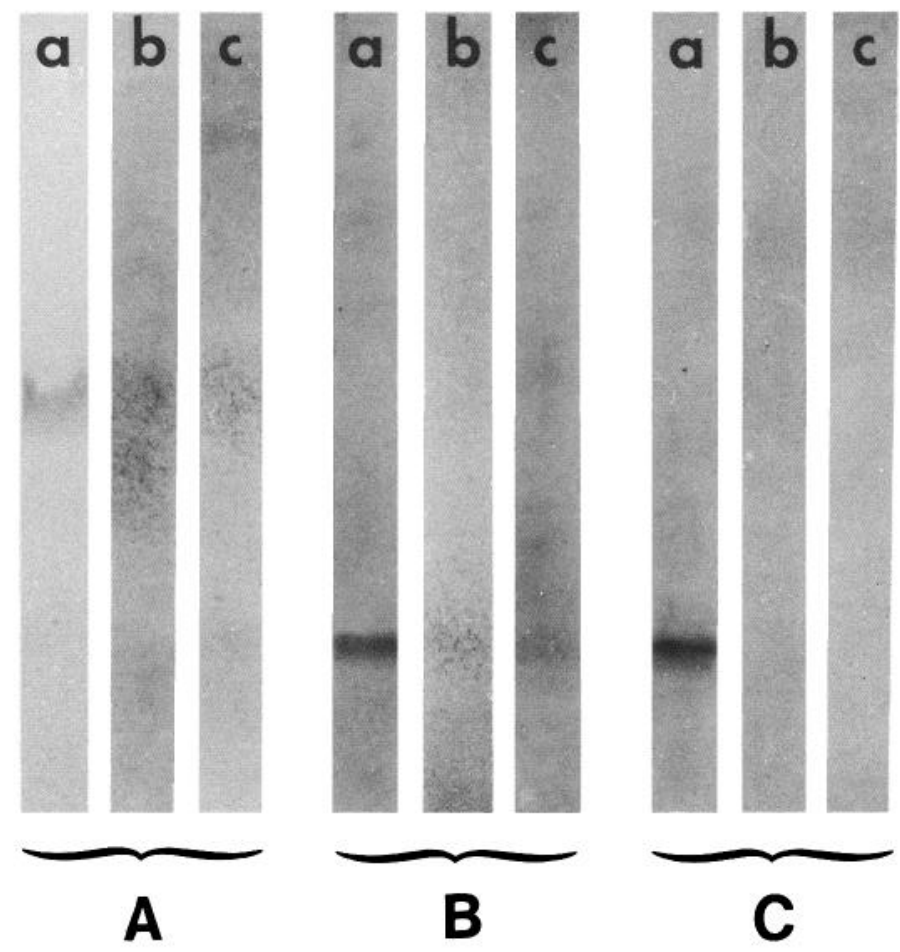

Figure 6. Western blots of (a) $1 \mu \mathrm{g}$, (b) $100 \mathrm{ng}$, or (c) $20 \mathrm{ng} \beta$-NGF. Before electrophoresis, samples were $(A)$ incubated at room temperature in the absence of $\beta$-mercaptoethanol, $(B)$ boiled for $10 \mathrm{~min}$ in the absence of $\beta$-mercaptoethanol, or $(C)$ boiled for $10 \mathrm{~min}$ in the presence of 0.6 м $\beta$-mercaptoethanol. $a$, Blots immunostained with anti-mouse NGF; $b$ and $c$, blots seeded with DRG 8 neurons for $48 \mathrm{hr}$ and incubated with MTT to visualize cell survival.

the other hand, exposure to SDS at higher temperatures with or without reduction induces the formation of monomers. Formation and trophic competence of dimer and monomer were examined in Western blots obtained from $\beta$-NGF after a 10 min exposure to $90^{\circ} \mathrm{C}$ in $2.3 \% \mathrm{SDS}$, in the absence or the presence of $0.6 \mathrm{M} \beta$-mercaptoethanol as a reducing agent. In each case, $\beta$-NGF was introduced in the sample buffer and loaded on gels in 3 different amounts: $1 \mu \mathrm{g} /$ lane for immunostaining of the resulting blots, 100 and $20 \mathrm{ng} /$ lane for cell-blotting evaluations. The results are compared in Figure 6 with corresponding loads of $\beta$-NGF under standard conditions $\left(2.3 \% \mathrm{SDS}, 4^{\circ} \mathrm{C}\right.$, no reducing agent).

In the standard conditions (Fig. 6A), all the immunostainable protein was in the $26 \mathrm{kDa}$ dimer form $(A, a)$, as already seen in Figure $3 B$. Cell-blot activity was expressed in the $26 \mathrm{kDa}$ region as a wider band ( $100 \mathrm{ng} /$ lane, $A, b)$ or a more restricted one (20 $\mathrm{ng} / \mathrm{lane}, A, c)$, and no activity was detected in the $13 \mathrm{kDa}$ region at either load. When $\beta$-NGF was boiled in sample buffer with no reducer before loading (Fig. $6 B$ ), all the immunostainable protein migrated to the $13 \mathrm{kDa}$ monomer region $(B, a)$, and the cell blot activity was similarly transferred to that region $(B, b$ and $c$ ). When the boiling of $\beta$-NGF was carried out in the presence of $\beta$-mercaptoethanol (Fig. $6 C$ ) conversion to the $13 \mathrm{kDa}$ form was equally complete $(C, a)$, but trophic activity was no longer detectable $(C, b$ and $c)$.

Conceivably, the $13 \mathrm{kDa}$ monomer may have redimerized during its transfer to the blot (which is carried out in the presence of $0.1 \%$ SDS in the blot buffer), and this blotted NGF might occupy the $13 \mathrm{kDa}$ position despite its new $26 \mathrm{kDa}$ size. We eluted the $13 \mathrm{kDa}$ monomer from the SDS-containing gel into
Table 2. Survival of CG8 and DRG8 neurons cultured on blots of different tissues crude extracts

\begin{tabular}{llllll} 
& \multicolumn{2}{l}{$\begin{array}{l}\text { NGF gel-blot } \\
\text { conditions }\end{array}$} & & \multicolumn{2}{l}{$\begin{array}{l}\text { CNTF gel-blot } \\
\text { conditions }\end{array}$} \\
\cline { 2 - 3 } \cline { 5 - 6 } Extract & CG8 & DRG8 & & CG8 & DRG8 \\
\hline CIPE & $+1-$ & - & & ++ & - \\
$\begin{array}{l}\text { Nerve } \\
\text { Submaxillary } \\
\quad \text { gland }\end{array}$ & $+/-$ & - & & ++ & - \\
\cline { 5 - 6 } & - & ++ & & - & -
\end{tabular}

100 trophic units were applied on the gel and corresponded to protein loads of 25,5 , and $0.2 \mu \mathrm{g}$ for extracts from CIPE, nerve, and submaxillary gland, respectively.

$0.2 \mathrm{ml}$ of SDS-free blot buffer. (Thus, if all the SDS eluted out of the gel with the NGF, the final concentration of SDS in the eluate from the gel would be $0.03 \%$.) We then incubated the gel eluate containing the NGF monomer overnight to allow any potential redimerization, mixed it with sample buffer (without boiling or reduction), and then reran it on the standard SDS gel. Silver staining of this gel showed that all the protein still ran in the $13 \mathrm{kDa}$ position (data not shown). This suggests that the biological activity localized within the $13 \mathrm{kDa}$ band of the cell blot was expressed by a truly monomeric immobilized NGF species.

\section{Discussion}

In this study, we report that (1) the cell-blot technique, initially established for CNTF, is also applicable to the study of one other neuronotrophic factor, NGF; (2) bound NGF has both survival and neuritic outgrowth effects; (3) the same target cells, the DRG10 neurons, will respond to bound CNTF by survival, and to bound NGF by survival plus neuritic outgrowth; (4) both the dimer and the monomer forms of $\beta$-NGF appear to be active.

Concerning point 1 , it was not initially evident that other neuronotrophic factors beside CNTF (which is very stable) would retain biological activity through treatments such as SDS-PAGE and electrophoretic transfer and that, conversely, other cells beside the ciliary ganglion neurons would be able to benefit from a surface-bound trophic factor. The extension of the cell-blot technique to NGF and its target cells encourages further attempts to use this technique with other types of factors, for example, trophic factors acting on CNS neurons or mitogens. The principal property of the cell-blot method is to allow, in a single experiment, the determination of both the apparent molecular mass and the level of activity of a substance, even if this substance is mixed with many others in a crude extract. This property could be exploited in studies such as (1) the comparison of the molecular weight and the activity of trophic factors contained in crude extracts from different tissues and different animal species; (2) the identification of one or more peptide fragments which retain activity after enzymatic digestion or chemical cleavage; (3) the simultaneous characterization of size and/or activity of mRNA translation products, before and after manipulation of the genes; or (4) the demonstration that an antibody or other interfering substance not only reacts with a precise molecule, but also blocks its biological activity.

Concerning point 2 , our study corroborates, using a different approach, the observations made by Frazier et al. (1973), Gundersen (1985), and Sandrock and Matthew (1987). The first group has shown that NGF bound to Sepharose beads retains its effects on the neuritic outgrowth from ganglionic explants; 
the second author has shown that bound NGF can guide the fibers growing from a ganglionic explant; the third showed that NGF can be bound to and express neurite outgrowth activity from degenerated but not normal peripheral nerve. None of these studies, nor the present one, provides any information as to whether the cell that encounters the anchored NGF needs to remove it from its anchorage in order to respond to it.

Concerning point 3 , the fact that the same target cells will respond by only survival when seeded on CNTF and by both survival and neuritic outgrowth when seeded on NGF blots implies that the neuritic outgrowth response is dictated by the type of factor rather than by the type of cell. NGF is able to exert by itself both survival and neuritic outgrowth effects. In contrast, cells allowed to survive by CNTF will need the presence of an another molecule, like laminin, to support the growth of their neurites (Davis et al., 1985, 1987). The cell-blot technique will allow us to address, in a new way, the role of NGF in neurite growth by cells that do not depend on NGF for their survival. It has been reported by Collins (1984) that NGF is able to accelerate the neuritic outgrowth of CG8 neurons cultured on a laminin-containing substratum. These studies had to be restricted to the first few hours in culture because the cells were cultured in the absence of any surviving factor. The cellblot approach may give the opportutnity to determine whether the survival and the neuritic outgrowth effects of NGF can be dissociated.

Concerning point 4 , NGF activity migrated in the $26 \mathrm{kDa}$ region under our standard conditions, whether NGF was loaded as its $7 \mathrm{~S}$ complex or its $\beta$-subunit form. The $26 \mathrm{kDa}$ band was recognized by antibodies against NGF, and its cell blot activity was blocked by the same antibody, demonstrating the NGF identity of the active blot. Conversion of the $26 \mathrm{kDa}$ dimeric form of $\beta-N G F$ to its monomeric one is completely achieved when NGF is heated in an SDS-containing sample buffer prior to electrophoresis. The cell-blot technique has allowed us to demonstrate that the $13 \mathrm{kDa}$ band is biologically competent with regard to both ncuronotrophic and neurite-promoting activities and that it loses these activities after sulfhydryl reduction. The fact that neuronotrophic factors can exert their effects in an immobilized form raises the question of their active location in vivo. The presentation of a trophic factor to its target cells in an anchored conformation may afford advantages compared to the humoral form, such as an increased stability of the activity, a better control of the topographical distribution, and a more specific action of the factor. It would also imply that the producing cell (or the storage cell) can be situated in the immediate proximity of the target cell, so that the anchored factor can be recognized by its receptors. The idea that a growth factor may occur in a bound position in vivo has been proposed by Gospodarowicz et al. (1986) for a class of mitogens, the heparinbinding growth factors. The physiological "heparin-presenting" material is the extracellular matrix. It has been therefore suggested that these factors could, in vivo, be sequestered by heparan sulfate proteoglycans embedded within the extracellular matrix.

The observation that NGF can promote neuritic outgrowth in a bound form may also offer possibilities to improve nerve regeneration. For example, it has been shown that NGF can prevent the disappearance of septal cholinergic neurons after transection of the fimbria-fornix pathways (Hefti, 1986; Williams et al., 1986; Kromer, 1987). However, even under NGF administration, axons are unable to cross the lesion space between the projecting neurons from the septum and the receiving neurons from the hippocampus, either because some com- pounds necessary for the regrowth are lacking or because the axons are able to grow but are not guided through the gap. The latter possibility could be studied by using, as a bridge across the gap, a piece of nitrocellulose paper presoaked in an NGF solution or, perhaps better, NGF anchored by electrophoretic transfer.

\section{References}

Aehersold, R. H., J. I eavitt, R. A. Saavedra, I. E. Hood, and S. B. H Kent (1987) Internal amino sequence analysis of proteins separated by one or two-dimensional gel electrophoresis after in situ protease digestion on nitrocellulose. Proc. Natl. Acad. Sci. USA 84: 6970 6974.

Angeletti, R., and R. A. Bradshaw (1971) Nerve Growth Factor from mouse submaxillary gland: Amino acid sequence. Proc. Natl. Acad. Sci. USA 68: 2417-2420.

Barbin, G., M. Manthorpe, and S. Varon (1984) Purification of the chick eye Ciliary Neuronotrophic Factor (CNTF). J. Neurochem. 43: 1468-1478.

Carnow, T. B., M. Manthorpe, G. E. Davis, and S. Varon (1985) Localized survival of ciliary ganglionic neurons identifies neuronotrophic factor bands on nitrocellulose blots. J. Neurosci. 5: 19651971.

Collins, F. (1984) An effect of nerve growth factor on the parasympathetic ciliary ganglion. J. Neurosci. 4: 1281-1288.

Davis, G. E., M. Manthorpe, and S. Varon (1985) Parameters of neuritic outgrowth from ciliary ganglion neurons: Influence of laminin, Schwannoma polyornithine-binding neurite promoting factor and ciliary neuronotrophic factor. Dev. Brain Res. 17: 75-84.

Davis, G. E., E. Engvall, S. Varon, and M. Manthorpe (1987) Human amnion membrane as a substratum for cultured peripheral and central nervous system neurons. Dev. Brain Res. 33: 1-10.

Frazier, W. A., L. F. Botd, and R. A. Bradshaw (1973) Interaction of Nerve Growth Factor with surface membranes: Biological competence of insolubilized Nerve Growth Factor. Proc. Natl. Acad. Sci. USA 70: 2931-2935.

Gospodarowicz, D., G. Neufeld, and L. Schweigerer (1986) Fibroblast growth factor. Mol. Cell. Endocrinol. 46: 187-204.

Greene, L. A., S. Varon, A. Piltch, and E. M. Shooter (1971) Substructure of the $\beta$ subunit of mouse $7 \mathrm{~S}$ nerve growth factor. Neurobiology $1: 37-48$.

Gundersen, R. W. (1985) Sensory neurite growth cone guidance by substrate absorbed Nerve Growth Factor. J. Neurosci. Res. 13: 199212.

Hefti, F. (1986) Nerve Growth Factor promotes survival of septal cholinergic neurons after fimbrial transections. J. Neurosci. 6: $2155-$ 2162.

Kromer, F. L. (1987) Nerve Growth Factor treatment after brain injury prevents neuronal death. Science 235: 214-216.

Levi-Montalcini, R. (1987) The Nerve Growth Factor: Thirty years later. In Vitro 23: 227-238.

Manthorpe, M., S. D. Skaper, R. Adler, K. B. Landa, and S. Varon (1980) Cholinergic neuronotrophic factors: Fractionation properties of an extract from selected chick embryonic eye tissues. J. Neurochem. 34: 69-75.

Manthorpe, M., S. D. Skaper, L. R. Williams, and S. Varon (1986) Purification of adult rat sciatic nerve ciliary neuronotrophic factor. Brain Res. 367: 282-286.

Rudge, J. S., G. E. Davis, M. Manthorpe, and S. Varon (1987) An examination of ciliary neuronotrophic factors from avian and rodent tissue extracts using a blot and culture technique. Dev. Brain Res. 32: $103-110$

Sandrock Jr., A. W., and W. D. Matthew (1987) Substrate-bound Nerve Growth Factor promotes neurite growth in peripheral nerve. Brain Res. 425: 360-363.

Selak, I., S. D. Skaper, and S. Varon (1983) Ionic behaviors and neuronal survival in developing ganglia. III. Studies with embryonic chick sympathetic neurons. J. Cell Physiol. 114: 229-234.

Towbin, H., T. Sarhelin, and J. Gordon (1979) Electrophoretic transfer of proteins from polyacrylamide gels to nitrocellulose sheets: Procedure and some applications. Proc. Natl. Acad. Sci. USA 76: 43504354. 
Varon, S. (1985) Factors promoting the growth of the nervous system. Discuss. Neurosci. 2: 1-62.

Varon, S., and R. Adler (1981) Trophic and specifying factors directed to neuronal cells. Adv. Cell Neurobiol. 2: 115-163.

Varon, S., J. Nomura, J. R. Perez-Polo, and E. M. Shooter (1972) The isolation and assay of the Nerve Growth Factor proteins. In Methods and Techniques of Neuroscience, R. Fried, ed., pp. 203-229, Dekker, New York.
Varon, S., M. Manthorpe, and R. Adler (1979) Cholinergic neuronotrophic factors. 1. Survival, neurite outgrowth and choline acetyltransferase activity in monolayer cultures from chick embryo ciliary ganglia. Brain Res. 173: 29-45.

Williams, L. R., S. Varon, G. Peterson, K. Wictorin, W. Fisher, A. Bjorklund, and F. H. Gage (1986) Continuous infusion of Nerve Growth Factor prevents basal forebrain neuronal death after fimbriafornix transection. Proc. Natl. Acad. Sci. USA 83: 9231-9235. 